\title{
Evaluation of diagnostic accuracy of FNAC and correlation with histopathology in thyroid lesions
}

\author{
C.P.Luck ${ }^{1}$, Jamunarani Srirangaramasamy ${ }^{2}$, Madasamy Balamurugan ${ }^{3}$, Balaji Arumugam $^{4}$, Aruna Padmavathy $^{5}$, \\ Revathy ${ }^{6}$
}

${ }^{1}$ Dr. C.P. Luck, Associate Professor, Department of Pathology, ${ }^{2}$ Dr. Jamunarani Srirangaramasamy, Associate Professor, Department of Pathology, ${ }^{3}$ Dr. Madasamy Balamurugan, Professor and HOD, Department of Pathology, ${ }^{4}$ Dr. Balaji Arumugam, Professor and HOD ${ }^{4}$, Department of Community Medicine, ${ }^{5}$ Dr. Aruna Padmavathy, Assistant Professor, ${ }^{6}$ Dr. Revathy, Assistant Professor, All authors are affiliated with Tagore Medical College \& Hospital, Rathinamangalam, Chennai, Tamilnadu, India.

Address for Correspondence: Dr. C.P Luck, M.D (Pathology), Associate Professor, Department of Pathology, Tagore Medical College \& Hospital, Rathinamangalam, Chennai. Tamilnadu, India. E-Mail: cpluckkamal@gmail.com

\begin{abstract}
:
Aim: The aim of the study is to evaluate the accuracy of FNAC diagnosis in non neoplastic \& neoplastic lesions of thyroid, and correlating with histopathological findings. Materials and Methods: This was a prospective study done in department of Pathology, Tagore medical college for a period of 3 years. 115 cases of thyroid subjected to FNAC where histopathology diagnosis was available were included in the study. The correlation of FNAC diagnosis with histopathology was made and the results were analysed. Results: The range of the age of the patient in this study was 25 to 60 years. The male to female ratio was $18.5: 81.5$. The maximum cases were colloid goitre $(59.2 \%)$ in which $12.5 \%$ were with features of papillary hyperplasia. Occurrences of dual pathology were seen in our study with one case of Hashimoto's thyroiditis with focus of papillary carcinoma and the other was medullary carcinoma with papillary carcinoma. 2 cases of anaplastic thyroid carcinoma were also seen. Conclusion: In our study sensitivity of FNAC in detecting thyroid lesions was $93.75 \%$, and the specificity was $97.01 \%$. FNAC of thyroid had a diagnostic accuracy of 95.65\% which clearly indicates that FNAC can be used as non invasive, cost effective and a safe diagnostic method for defining thyroid disorders.
\end{abstract}

Keywords: Thyroid lesions, FNAC, Cystic papillary carcinoma, Dual pathology, Diagnostic accuracy.

\section{Introduction}

Fine needle aspiration cytology (FNAC) is a cost effective and a simple office procedure which gives a quick diagnosis at the first contact of the patient. It can delineate between benign and malignancy and can be repeated for definite confirmation of diagnosis [1]. FNAC being a minimally invasive technique is particularly suitable in thyroid where an incisional biopsy may present problems. The lesions in thyroid are varied ranging from inflammation to neoplasm. FNAC of thyroid helps us to categorize the lesions which require surgical intervention and those which do not [24]. $95 \%$ of the thyroid lesions are benign. Only 5\% are malignant which requires immediate intervention. The

Manuscript received: $30^{\text {th }}$ April 2017

Reviewed: $8^{\text {th }}$ May 2017

Author Corrected: $17^{\text {th }}$ May 2017

Accepted for Publication: $24^{\text {th }}$ May 2017 anaplastic and poorly differentiated lesions can be planned for palliative radiotherapy or chemotherapy $[5$, 6]. The purpose of FNAC is that it is not a substitute for histopathology and if it is used in conjunction with clinical and radiological parameters it will provide the best initial assessment on which management decisions can be based.

It is true that the increasing use of ancillary techniques such as immunohistochemistry, electron microscopy, cytogenetics and molecular biology techniques has significantly enhanced the potential to make a precise type-specific diagnosis but they are expensive and not done as a routine, can be applied in problematic cases. Hence FNAC is still a simple and less time consuming to detect thyroid lesions. However, the limitations of 
FNAC are the representativeness of area, adequacy of material aspirated and the quality of slide preparation. If these advantages are overcome, FNAC is the best modality of detecting thyroid lesions.

\section{Materials and Methods}

Study design: This was a prospective study done in department of Pathology, Tagore medical college and Hospital from May 2013 to March 2016.

Sample size: The study comprised of 710 cases of thyroid lesions subjected to FNAC. Out of which 595 cases were managed medically which were not included in the study. Only 115 cases managed surgically were included in the study. The age group included were patients from 25 years to 60 years.

Inclusion criteria: The thyroid lesions were clinically defined as benign or malignant before aspiration and radiological assistance was obtained wherever necessary. Thyroid cases managed surgically where the tissue sent for histopathology were included in the study.

Exclusion criteria: Thyroid cases with FNAC diagnosis which required only medical intervention were excluded from the study.

\section{Methodology}

Age, Sex, duration of swelling, detailed clinical examination, features of hyper and hypothyroidism was recorded, wherever necessary. Thyroid function tests were used as a diagnostic tracer. Correlation of iodine uptake study was advised in doubtful cases to rule out follicular neoplasm. Fine needle aspiration was done for the above cases and the results were interpreted. The cytological findings were categorized as follows.

1. Neoplasm-Benign-Follicular adenoma.

2. Malignant- Papillary carcinoma, medullary carcinoma, anaplastic Carcinoma.

3. Non neoplastic lesion - Goitre, Hashimoto's Thyroiditis, Lymphocytic Thyroiditis, Thyroglossal Cyst. Inconclusive -Advised biopsy.

The thyroid cases with FNAC diagnosis were subjected to surgery. The resected tissues were examined histologically and the findings were correlated with the corresponding FNAC results.

Data analysis: The data was entered in MS excel sheet and analysis was done in SPSS software. The datas were expressed in percentage and evaluation was done.

\section{Results}

The age of the patients who presented in this study was in between 25- 60 yrs. Males were $18.5 \%$ and Females were $81.5 \%$. $60 \%$ of the patients presented with hypothyroidism, $10 \%$ with hyperthyroidism and $30 \%$ of the patients were euthyroid. The most common diagnosis was colloid goitre which constituted around 59.2\%. Among those with colloid goitre, $12.5 \%$ of cases presented with papillary hyperplasia. Predominant cases of hashimato's thyroiditis showed a diffuse pattern. The incidence of papillary carcinoma was found to be high in middle age females where as the incidence of anaplastic carcinoma was seen in middle age males. Two cases revealed dual pathology. One case was Hashimoto's thyroiditis with a focus of papillary carcinoma and the other case was medullary carcinoma with papillary carcinoma. The case distribution according to cytology diagnosis was represented in Table1.

Table-1: Case distribution according to Cytology Diagnosis.

\begin{tabular}{|c|c|c|}
\hline $\begin{array}{c}\text { S. } \\
\text { No }\end{array}$ & Cytological diagnosis & Number of Cases \\
\hline 1. & Goitre & 55 \\
\hline 2. & Thyroiditis & 5 \\
\hline 3. & Thyroglossal cyst & 35 \\
\hline 4. & Follicular adenoma & 12 \\
\hline 5. & Malignancy & $\mathbf{1 1 5}$ \\
\hline \multicolumn{2}{|c|}{ Total } & 8 \\
\hline
\end{tabular}

The cytology diagnosis was correlated with histopathology which is the golden standard. Cytology correlation with histopathology was shown in Table 2. 
Research Article

Table-2: Cytology correlation with histopathology diagnosis.

\begin{tabular}{|c|c|c|c|}
\hline Cytologic Diagnosis & $\begin{array}{c}\text { Total } \\
\text { number }\end{array}$ & Histopathological Diagnosis & Total number \\
\hline \multicolumn{4}{|c|}{ Non neoplastic (68) } \\
\hline \multirow[t]{2}{*}{ Nodular Goitre } & 55 & Nodular Goitre & 53 \\
\hline & & Follicular Neoplasm & 2 \\
\hline \multirow[t]{2}{*}{ Hashimoto's Thyroiditis } & 5 & Hashimoto's Thyroiditis & 4 \\
\hline & & Hashimoto's Thyroiditis with papillary carcinoma & 1 \\
\hline Thyroglossal cyst & 8 & $\begin{array}{c}\text { Thyroglossal cyst } \\
\end{array}$ & 8 \\
\hline \multicolumn{4}{|c|}{ Neoplastic (47) } \\
\hline \multirow[t]{3}{*}{ Follicular Adenoma } & 35 & Follicular Adenoma & 32 \\
\hline & & Follicular variant of papillary carcinoma & 1 \\
\hline & & Nodular Goitre & 2 \\
\hline Papillary Carcinoma & 10 & Papillary Carcinoma & 10 \\
\hline Medullary Carcinoma & 2 & Medullary Carcinoma & 2 \\
\hline Total & 115 & Total & 115 \\
\hline
\end{tabular}

Out of 55 cases of goitre, 53 cases were concordant. Two cases of nodular goitre with epithelial hyperplasia showed in histopathology features of follicular adenoma. In this series of 35 patients diagnosed by cytology as follicular adenoma, three cases deferred in histopathology correlation. One case was diagnosed as a follicular adenoma with focal papillary carcinoma in histology. This sampling error is because the focal papillary carcinoma area was not struck during aspiration. Only two cases were diagnosed as nodular goitre which implies a false positive score of 2 . However, in malignancy, two cases of papillary carcinoma were missed in dual pathology. The overall correlation of FNAC with histopathology is represented in Table3.

Table-3: Overall correlation of FNAC with histopathology of thyroid.

\begin{tabular}{|c|c|c|c|}
\hline \multirow{3}{*}{ FNAC } & \multicolumn{3}{|c|}{ HISTOPATHOLOGY } \\
\cline { 2 - 4 } & Neoplastic & Non neoplastic & Total \\
\cline { 2 - 4 } & 45 & 2 & 67 \\
\cline { 2 - 4 } & 3 & 65 & $\mathbf{1 1 5}$ \\
\hline \multirow{2}{*}{ Total } & $\mathbf{4 8}$ & $\mathbf{6 7}$ & 68 \\
\hline
\end{tabular}

The sensitivity of FNAC in diagnosing thyroid lesions was $93.75 \%$ and the specificity was $97.01 \%$. The Positive predictive value was $95.74 \%$, Negative predictive value was $95.58 \%$, False positive rate was $2.98 \%$, False negative rate was $6.25 \%$, Diagnostic accuracy was $95.65 \%$

\section{Supplementary Data:}

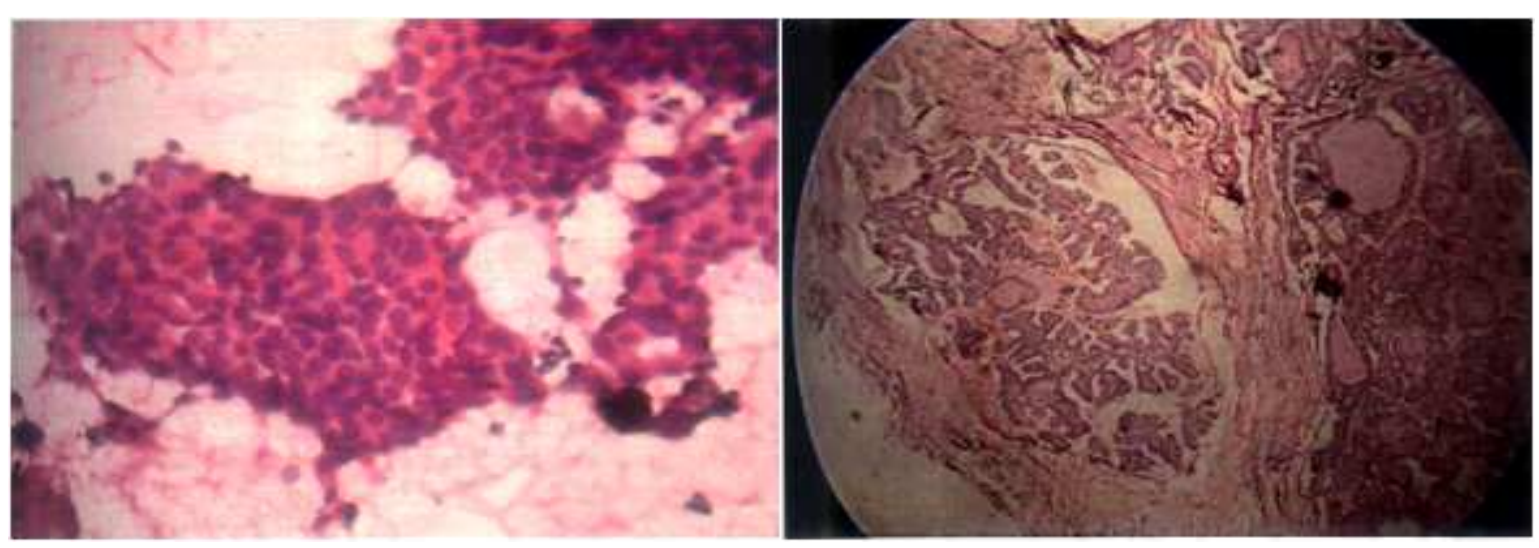

Figure-1: FNAC and histopathology of papillary Carcinoma 

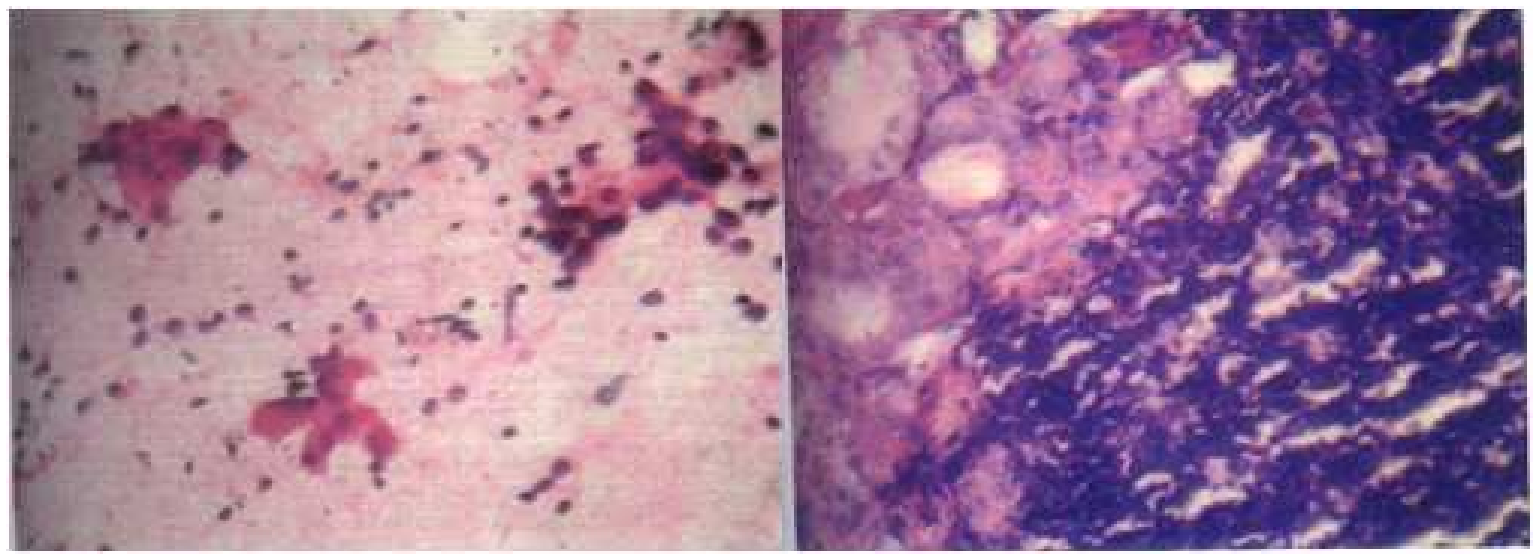

Figure-2: FNAC and histopathology of Hashimato's thyroiditis

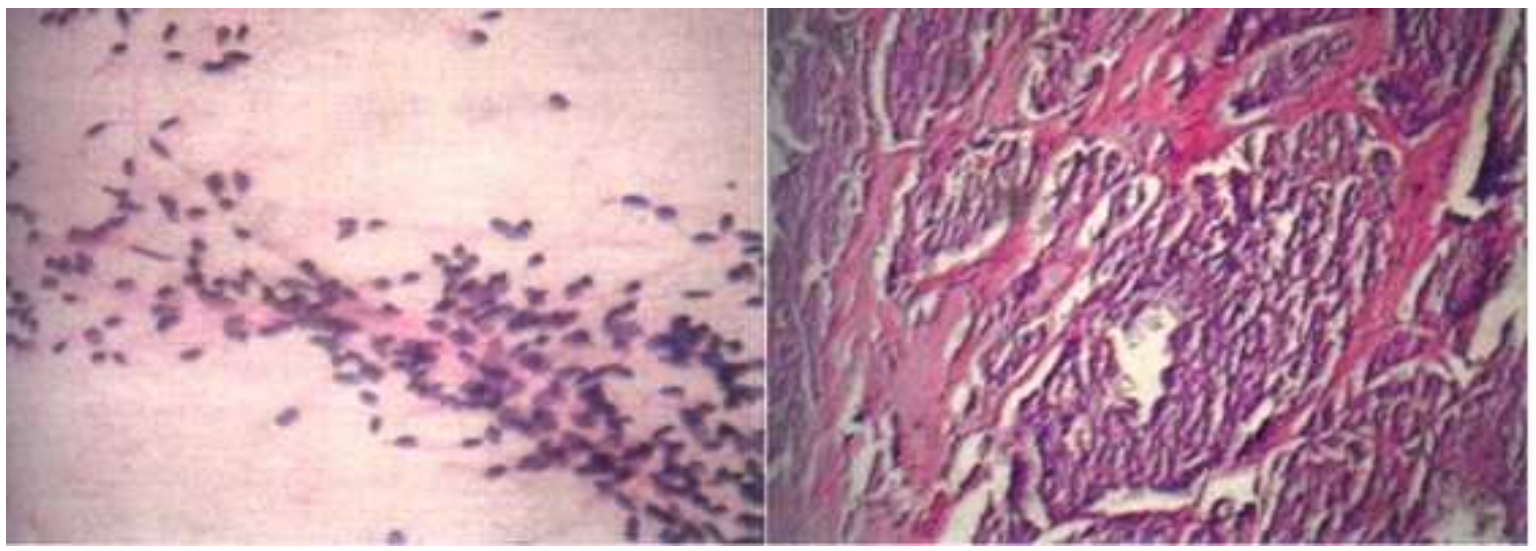

Figure 3: FNAC and histopathology of Medullary Carcinoma

\section{Discussion}

The current study was done to evaluate the diagnostic accuracy of FNAC and to correlate FNAC with histopathology in thyroid lesions. One of the organs in our body where FNAC has wide application is the thyroid. A team work among pathologist, clinicians, and radiologists is essential to yield the best results in FNAC. Hence FNAC can be used as a safe diagnostic method for categorizing the thyroid lesions [7]. In our study there was a female preponderance with malefemale ratio of 18.5: 81.5 similar to KumarS et al study [7]. Benign cases were most common. Most of the cases among benign lesions were nodular goiter. Papillary carcinoma thyroid was most common among malignancy.

In our study the data analysed showed sensitivity of FNAC in detecting thyroid lesions is $91.6 \%$, specificity is $97.01 \%$. FNAC has a positive predictive value of $95.6 \%$ and negative predictive value of $94.2 \%$. Our data is comparable with other published datas in which the range of sensitivity $65 \%$ to $98 \%$, specificity $72 \%$ to $100 \%$, PPV $34 \%$ to $100 \%$ NPV $83 \%$ to $100 \%$ [8].
The diagnostic accuracy in our study is $94.78 \%$ which is concordant with other published data which reveals $95 \%$ in the differentiation of benign from malignant nodules in thyroid glands [4]. The false negative rate in our study was $8.3 \%$. False positive rate was $2.98 \%$

In our study 2 cases of follicular adenoma were reported as colloid goiter and 2 cases of nodular goiter were reported as follicular adenoma Clary et al have referred this inter observer variability in their study [9]. However overlapping epithelial hyperplasia and neoplasia is unavoidable. This sampling error could have been overcome by repeat aspiration [10]. One case of follicular adenoma in our study revealed features of papillary carcinoma in histopathology.

Confusion between follicular adenoma and papillary carcinoma is unavoidable especially in follicular variant of papillary carcinoma [11] as the smear revealed tumor cells arranged in follicles without colloid. Mundasad et al have referred that indefinite to diagnose nodules should be subjected to surgery for conformation [12]. 
Research Article

Aspiration cytology is not very effective in predicting neoplasia in cystic thyroid swellings. The cystic change could be seen in congenital, nodular hyperplasia, and neoplastic entities like cystic papillary thyroid carcinoma and rarely in follicular neoplasm. Only 10$15 \%$ of the cysts are neoplastic. In our study, out of 10 cases of papillary carcinoma of thyroid, 2 cases presented with a cystic swelling. In both the cases, the centrifuged material from the aspirate revealed papillary architecture with nuclear features of malignancy. Borget et al. have told that guided FNAC would be an aid in proper diagnosis in such cases [13].

The cytologic accuracy with largely degenerated nodules is lower, in that the ability to differentiate benign and malignant follicular neoplasm is limited. It is important not only to enhance the specificity of preoperative diagnosis but also to increase simultaneously the sensitivity of detection. So those patients with carcinoma are discovered early for effective therapy. Bukhari et al. in their study of the FNAC procedure of the solitary thyroid nodule strongly suggest that FNAC should be used as an initial investigation of thyroid diseases, in all tertiary hospitals [14].

The transition of differentiated thyroid carcinoma to anaplastic thyroid cancers seems to be well established [9]. The incidence of anaplastic carcinoma in our present study is two cases in middle-aged persons. About $20 \%$ to $30 \%$ of all giant cell anaplastic carcinomas have a long history of thyroid swelling more than 15 years. Thus one type of very serious thyroid neoplasm can be prevented by early detection highlighting the role of FNAC as a screening procedure in the high-risk group [15].

The incidence of dual pathology was seen in 2 cases. One was Hashimoto's thyroiditis with papillary carcinoma. The other was medullary carcinoma with papillary carcinoma. In both these cases, we arrived at only one diagnosis. In both these cases, papillary carcinoma foci were not struck during aspiration.

Chronic thyroiditis can coexist with many types of thyroid cancers and we overlooked the neoplastic lesion in the above cases. This sampling error could have been avoided if repeat aspiration was performed. False negative diagnosis arises from inadequate samples, geographic misses of lesions, dual pathology, and errors of interpretations and also in relation to the cystic neoplasm. This is of great concern because it indicates the potential to miss the malignant lesions [16].

\section{Conclusion}

The results of the accuracy of FNAC in thyroid vary but in most series, overall accuracy rate exceeds $90 \%$ with $5-10 \%$ frequency of false positive and false negative. Diagnostic accuracy found in this study was $95.65 \%$ and false positive rate $2.98 \%$ false negative rate $6.25 \%$.

The present study confirms the view that FNAC has potential ability to detect both benign and malignant lesions of thyroid with accuracy. Thus FNAC can be used as non invasive, cost effective and a safe diagnostic method for defining thyroid disorders. It can be used as a screening test and helps in selection of patients for the appropriate treatment modality.

Funding: Nil, Conflict of interest: None initiated, Permission from IRB: Yes

\section{References}

1. Jameson JL, Weetman AP. Disorders of the thyroid gland. Harrisons principles of internal medicine. 2001; 2:2060-83.

2. Das KD, Khanna CM, Tripathi RP, Pant CS, Mandal AK, Chandra S,et al. Solitary nodular goiter: Review of cytomorphologic features in 441cases. Acta Cytol 1999; 43(4):563-74.

3. Afroze N, Kayani N, Hasan SH. Role of fine needle aspiration cytology in the diagnosis of palpable thyroid lesions. Indian J Pathol Microbiol.2002 Jul;45(3):241-6.

4. Handa U, Garg S, Mohan H, Nagarkar N. Role of fine needle aspiration cytology in diagnosis and management of thyroid lesions: A study on 434 patients. J Cytol 2008;25(1):13-7.

5. Yeung MJ, Serpell JW. Management of the solitary thyroid nodule. Oncologist. 2008 Feb;13(2):105-12. doi: 10.1634/theoncologist.2007-0212.

6. Esmaili HA, Taghipour H. Fine-needle aspiration in the diagnosis of thyroid diseases: An appraisal in our institution. ISRN Pathology. 2012 Sep 3;2012.

7. Kumar S, Aqil S, Dahar A. Role of fine needle aspiration cytology in thyroid diseases. J Surg Pak 2008;13(1):22-5. 


\section{Research Article}

8. Cap J, Ryska A, Rehorkova P, Hovorkova E, Kerekes Z, Pohnetalova D. Sensitivity and specificity of the fine needle aspiration biopsy of the thyroid: clinical point of view. Clin Endocrinol (Oxf). 1999 Oct 1;51(4):509-15.

9. Clary KM, Condel JL, Liu Y, Johnson DR, Grzybicki DM, Raab SS. Interobserver variability in the fine needle aspiration biopsy diagnosis of follicular lesions of the thyroid gland. Acta cytologica. 2005 Jul 1;49 (4):378-82.

10. Somma J, Schlecht NF, Fink D, Khader SN, Smith $\mathrm{RV}$, Cajigas A. Thyroid fine needle aspiration cytology: follicular lesions and the gray zone. Acta Cytol. 2010 Mar-Apr;54(2):123-31.

11. Gupta S, Sodhani P, Jain S, Kumar N. Morphologic spectrum of papillary carcinoma of the thyroid: role of cytology in identifying the variants. Acta Cytol. 2004 Nov-Dec;48(6):795-800.

12. Mundasad B, Mcallister I, Carson J, Pyper P. Accuracy of fine needle aspiration cytology in diagnosis of thyroid swellings. Internet $\mathbf{J}$ Endocrinol. 2006;2(2)
13. Borget I, Vielh P, Leboulleux S, Allyn M, Iacobelli S, Schlumberger M, de Pouvourville G. Assessment of the cost of fine-needle aspiration cytology as a diagnostic tool in patients with thyroid nodules. Am J Clin Pathol. 2008 May;129(5):763-71. doi: 10.1309/ H86KM785Q9KBWPW5.

14. Bukhari MH, Niazi S, Hanif G, Qureshi SS, Munir M, Hasan M, Naeem S. An updated audit of fine needle aspiration cytology procedure of solitary thyroid nodule. Diagn Cytopathol. 2008 Feb;36(2):104-12. doi: 10.1002/dc.20731

15. Stavrić GD, Karanfilski BT, Kalamaras AK, Serafimov NZ, Georgievska BS, Korubin VH. Early diagnosis and detection of clinically non-suspected thyroid neoplasia by the cytologic method: a critical review of 1536 aspiration biopsies. Cancer. 1980 Jan $15 ; 45(2): 340-4$.

16. Kantasueb SA, Sukpan KO, Mahanupab PO. The study of thyroid lesions and the correlation between histological and cytological findings. Chiang Mai Med J 2010;49(3):105-10

\section{How to cite this article?}

C.P.Luck, Jamunarani Srirangaramasamy, Madasamy Balamurugan, Balaji Arumugam, Aruna Padmavathy, Revathy. Evaluation of diagnostic accuracy of FNAC and correlation with histopathology in thyroid lesions. Trop J Path Micro 2017;3(2):96-101.doi: 10.17511/jopm.2017.i2.03. 